\section{OPEN JOURNAL SYSTEMS}

ISSN:2237-2202

\section{Available on line at Directory of Open Access Journals}

Journal of Hyperspectral Remote Sensing v.9, n.1 (2019) 30-35

www.periodicos.ufpe.br/revistas/jhrs

\section{Journal of Hyperspectral Remote Sensing www.ufpe.br/jhrs}

\title{
Air temperature and relative moisture oscillations in Recife - PE
}

\author{
Manoel V. de França ${ }^{*}$, Romildo M. Holanda", Raimundo M. de Medeiros ${ }^{* *}$ \\ *Prof. MSc. Federal Rural University of Pernambuco, UFRPE, PE, Brazil, e-mail: manoelvieiraufrpe@gmail.com \\ "Prof. Dr. Federal Rural University of Pernambuco, UFRPE, PE, Brazil, e-mail: romildomorant@gmail.com \\ ${ }^{* *}$ Prof., Post Doc, Dr. Adelmar Furtado Faculty, Teresina, Piauí - Brazil \\ E-mail: mainarmedeiros@gmail.com
}

Received 07 December 2018, accepted 30 March 2019

\begin{abstract}
The objective of this study was to study temperature variability and relative humidity, comparing the 1962-1990 and 19912016 periods with the averages of 1931-2016 and 1962-2016, respectively, with the aim of quantifying climate change and identifying the influence Of large-scale El Niño events, aiming to contribute to the managers responsible for urban planning and improving the quality of life of the inhabitants and the ecosystem. Air temperature and relative humidity data provided by the National Institute of Meteorology (INMET) were used. Basic statistical parameters were calculated as: mean, standard deviation, coefficient of variance, variations of annual anomalies in order to identify buoyancy in the data and the influence of extreme events. The city of Recife suffered from disorderly growth, with no specific patterns of planning in urbanization that caused variations in the microclimate of the urbis, causing thermal discomfort and reducing the quality of life of its inhabitants. There is intense flow of automotive vehicles and people throughout the day due to activities related to work, commerce and services, as well as the concentration of various buildings, waterproofed areas as well as buildings, making the local air circulation difficult. It is suggested an increase in green areas from the afforestation that has been shown as an alternative to improve the quality of life in urban spaces.
\end{abstract}

Keywords: climatic influences, microclimate variations, extreme events.

\section{Introduction}

Climate is a set of physical, chemical and biological elements that characterize the atmosphere of a place and influence the beings that are in it (Pereira et al., 2001). Therefore, it is considered one of the most important variables of the environment. However, human activities can contribute in a negative way, gradually changing the environment interfering in the urban ecosystem, thus causing changes in the quality of life of society in general. The difference in the thermal response between urban and rural environments is mainly marked by the development of heat islands in urban areas, according to Rocha (2011). Parker (2010) clarifies that heat islands are the result of the physical properties of buildings and other structures. In addition, the emission of heat by human activities occurs.

The relative humidity of the air is influenced by some important climate controls like the temperature, even if there is no increase or reduction of humidity, that is, it is inversely proportional to temperature. The humidity is strongly concentrated in the low layers of the atmosphere (in the first 2,000 meters of altitude), generally it reduces reduction of the humidity with the increase of the altitude. Soil use and vegetation cover predominate in a given region and express the interactions between the available energy (radiation balance) to the surface-atmosphere system and its partition in sensible heat (air heating) and latent (evaporation) flows. It is also known that locations with exposed and dry soil tend to have higher temperatures and lower relative humidity when compared to those environments with more preserved vegetation cover and, consequently, more humid, for the same amount of available energy.

There are also the effects of moisture on the thermal sensation, because the wetter the environment, the greater the effects of temperature on the population of the city. Thus, where it is hot, if the humidity increases, the "choke" will increase, making the thermal sensation much better than the actual air temperature. On the other hand, if it is becoming cold and the humidity is sharp, the effects of the cold tend to be greater, diminishing the thermal sensation. The ideal for many is dry cold and dry heat, although it is important that the levels of relative humidity in the air are not extremely low.

One of the most important effects of solar radiation is air temperature. Part of the radiant energy reaching the earth's surface is used to heat the soil, which in turn heats the air in contact with the surface, by transporting the sensible heat by molecular 
conduction and turbulent diffusion in the mass of air in accordance with Ometto (1981). In the layer of air in contact with the soil, the maximum temperatures of the soil and air occur simultaneously, however, as it moves away from the surface, the instant of occurrence of the maximum air temperature is being delayed in relation to the instant of occurrence Of the maximum soil temperature according to Pereira et al. (2002).

Studies on extreme events conducted in South America through the analysis of trends in temperature indices according to Vincent et al. (2005) indicated an increase in the minimum temperature and demonstrating that there has been a reduction of cold nights and becoming scarce and provoking an increase in the thermal amplitude, this confirmation was also reported by Berlato et al. (2010).

In the last decade significant temperature increases have been observed in different cities of the world in accordance with the IPCC (2007); Marengo (2001); Kalnay et al. (2003). On the Amazon basin, Marengo (2001) estimated the heating in the order of $+0.85^{\circ} \mathrm{C} / 100$ years. This author also showed that warming can vary by region, and may be due to natural factors or anthropogenic factors such as heat island and the urbanization effect of large cities, or due to the combination of the two. Changes in the earth's surface, such as urbanization, which have the effect of replacing natural surfaces with buildings, have increased the waterproofing of soils and the irradiation of heat to the atmosphere according to Sousa et al. (2012) and Chen et al. (2006). One of the best known anthropogenic influences on climate is the phenomenon of urban heating. The increase of surface or air temperature over an urban area in relation to neighboring rural or suburban areas is called Heat Island according to the authors Arya (2001); Freitas et al. (2005). And the difference in the air temperature of an urban area in relation to its neighborhood provides the intensity of the heat island according to Memon et al. (2009) and Hung et al. (2006).

The objective of this study was to analyze the climatic variability of the city of Recife - PE, using the meteorological factors: air temperatures and relative humidity of the periods 1931-1960; 19611990; 1991-2016 and comparing between the climatological normal of the period (1962-2016) seeking to quantify possible climatic changes in the values of maximum, minimum and average temperatures and the relative humidity of the air, will also be analyzed the anomalies related to the occurrence of extreme climatic events of El Niño aiming at subsidies to the population to the public power and to the decision makers with their urban and environmental planning aiming to improve the quality of human and animal life and in case of extreme events occurring with a view to the improvements in the conditions, agriculture, In the supply and storage of water in the study area.

\section{Materials and methods}

Recife is bordered to the north by the cities of Olinda and Paulista, to the south by the municipality of Jaboatão dos Guararapes, to the west by São Lourenço da Mata and Camaragibe, and to the east by the Atlantic Ocean. Located at latitude $08^{\circ} 01^{\prime} \mathrm{S}$; Longitude $34^{\circ} 51^{\prime} \mathrm{W}$, with average altitude in relation to sea level of 72 meters (Figure 1).

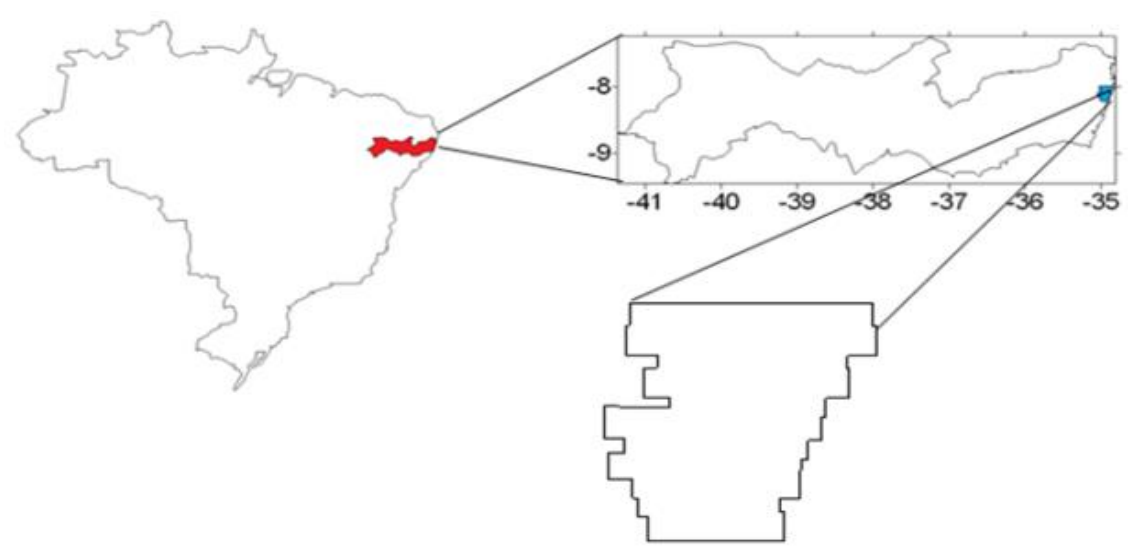

Figure 1 - Location of the city of Recife - PE.

Data of temperature and relative humidity of the air, given by the National Institute of Meteorology (INMET, 2016), for Recife - PE, from the periods 1962-2016; 1962-1990 and 1991-2016 (temperature and relative humidity), and were compared to each other to observe an increase or decrease in the values of the temperatures and the relative air humidity of the studied area. The mean monthly and annual total values and statistical calculations were calculated as the mean, standard deviation and coefficient of variation, where the standard deviation and the coefficient of variation measure the variability of the 
analyzed series, in order to compare with the climatological pattern, Of the Norms studied. Based on the averages, the annual anomalies $(\mathrm{Xi}-\mathrm{X})$ were calculated, where $\mathrm{Xi}$ is the variable and $\mathrm{X}$ is the average of the Climatological Normal, to show how much, each year it departs from the average climatological value and these distances can be negative (Dry periods) or positive (rainy season). With the obtained values, they produced graphs, with the purpose of verifying possible changes and / or transformations, being through the calculations of the anomalies that will be identified the years of occurrence of El Niño (a), thus defining, the variability of the meteorological elements under study.

According to Sousa et al. (2013) atmospheric systems, which most contribute to the precipitation of the Metropolitan Region of Recife, are the Frontal Systems (less frequently), the Eastern Wave Disorders and the Sea and Land Breezes, the latter being originated in the Ocean Atlantic; Leste waves are more common in autumn / winter, pushed by the south-east trade, they reach the eastern coast of the Northeast, bringing heavy rainfall, another precipitation inductor is the Intercultural Zone of Conversion ), A perturbation associated with the expansion to the southern hemisphere of the thermal equator (the heat rise zone of the trade by thermal convection).

The ITCZ hits Reef, especially in the fall, and causes stormy rains and changes in the direction of the $\mathrm{SE}$ winds to NE, or even, calms. Due to the irregularity space of its occurrence, year to year is subject to great variability. The formations of Vortex Systems of High Levels (VCAS) during their formations in the months of February to April and with their edges on the NEB, especially above the state of Pernambuco, increase the cloud cover and provoke high intensity and short rains Flooding, floods and the socioeconomic sector. The heavy rains that occur in the region during the rainy season are influenced by the continental equatorial mass, which conditions convective movements of the Northeast and Southeast alísios; Intertropical Convergence Zone (ITCZ); The effects of sea / land breeze and sea surface temperature in the dry period recorded rainfall is caused by local contributions forming cloud followed by isolated precipitation.

\section{Results and discussion}

The Figure 2 shows the minimum monthly air temperature variability for the periods 1962-1990 and 1991-2016 and its comparison with the average temperature of the series from 1962 to 2016 for the city of Recife - PE.

The minimum average temperature of the period 1991-2016 showed oscillation between $20.9^{\circ}$ $\mathrm{C}$ in the month of August to $23.4^{\circ} \mathrm{C}$ in the months of February and March with a minimum annual temperature of $22.4^{\circ} \mathrm{C}$. The annual temperature of $21.8^{\circ} \mathrm{C}$ with oscillations between 20.6 in August and $22.7^{\circ} \mathrm{C}$ in the month of March were the temperature conditions from 1962-1990 for the municipality of Recife - PE. The annual temperature of $22.1^{\circ} \mathrm{C}$ and the respective oscillations of $20.7^{\circ} \mathrm{C}$ in the month of August $22.4^{\circ} \mathrm{C}$ in the month of February to March were to the conditions of registration in the series of minimum temperature of 1962-2016. The standard deviations of the $1962-2016$ series ranged from 0.6 to $1.1^{\circ} \mathrm{C}$ and their coefficients of variance ranged from 0 to $0.1^{\circ} \mathrm{C}$, showing larger dispersions around the mean.

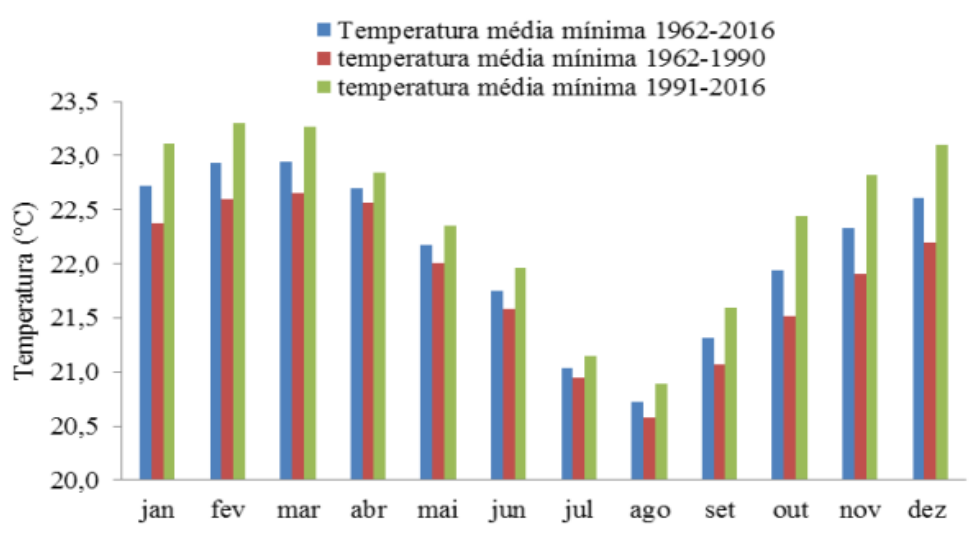

Figure 2 - Minimum monthly air temperature for the periods 1962-1990 and 1991-2016 and its comparison with the average temperature of the series and 1962 - 2016 for the municipality of Recife - PE. Source: INMET (19622016). 
During the periods in accordance with Figure 3, the minimum temperature anomalies for the periods 19621990 are observed; 1991-2016 for the municipality of Recife - PE. It is noteworthy that in the period 19912016 the anomalies were more significant in that period when compared with the period 1962-1990.
There are eight positive anomalies in the period $1962-$ 1990 and four negative anomalies in the period 19912016. The minimum temperatures are rising from the year 1966 to the present day except the years of 2011 and 2012 according to Figure 3.

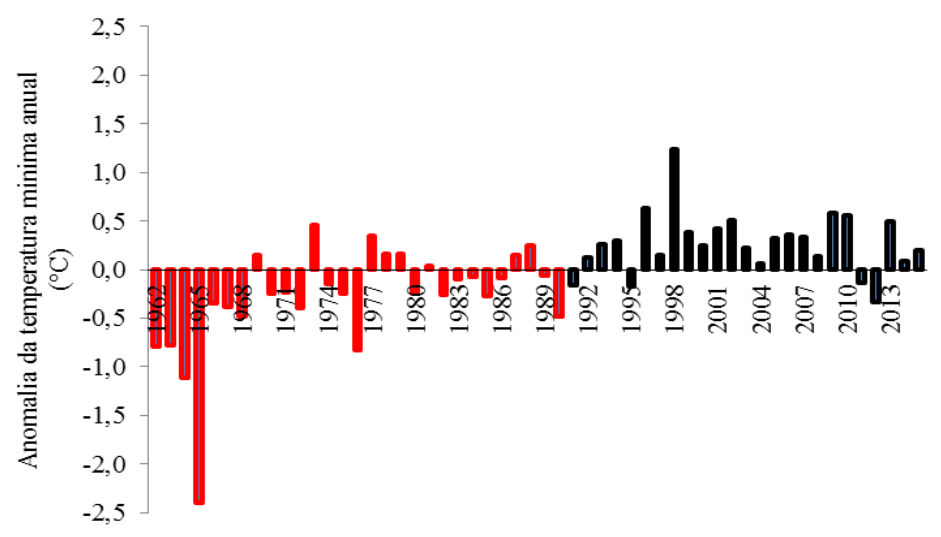

Figure 3 - Minimum temperature anomalies, for the periods 1962-1990; 1991-2016 for the municipality of Recife PE. Source: INMET (1962-2016).

The Figure 4 shows the monthly maximum air temperature variability for the periods 1962-1990 and 1991-2016 and its comparison with the average temperature of the series and 1962 - 2016 for the city of Recife - PE.

The maximum temperature ranges from $30.5^{\circ}$ $\mathrm{C}$ in January, February and March to $27.6^{\circ} \mathrm{C}$ in July, with an annual average of $29.3^{\circ} \mathrm{C}$. The maximum coefficient of variance was $0.1^{\circ} \mathrm{C}$. The standard deviation from the mean ranges from 0.5 to $1.5^{\circ} \mathrm{C}$, showing larger dispersions around the mean.

During the period 1962-1990, the annual temperature was $29.1^{\circ} \mathrm{C}$ with monthly oscillations of $27.4^{\circ} \mathrm{C}$ in July at $30.3^{\circ} \mathrm{C}$ in January. The maximum annual temperature of $29.6^{\circ} \mathrm{C}$ for the period 1991 2016 and its monthly fluctuations occurred between $27.8^{\circ} \mathrm{C}$ in the months of July and August at $30.9^{\circ} \mathrm{C}$ in the months of March and April.

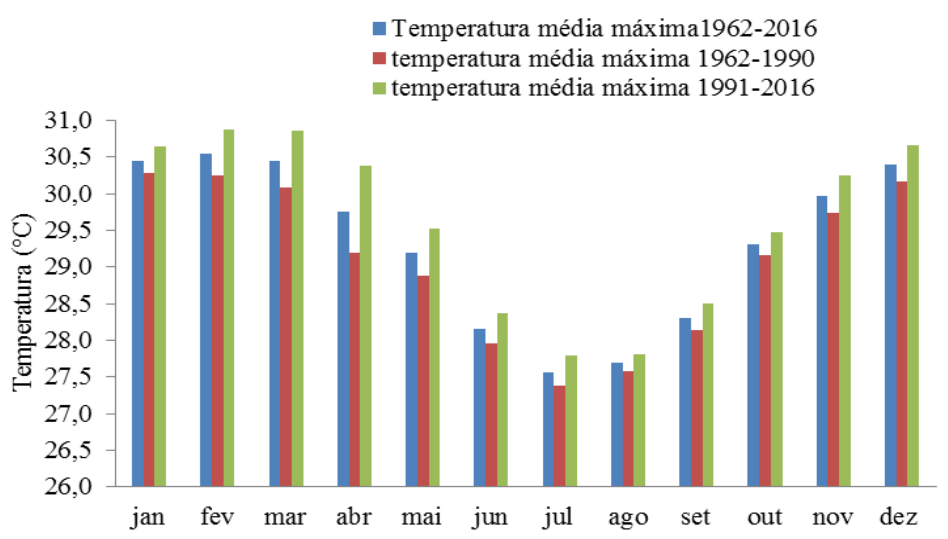

Figure 4 - Average monthly air temperature for the periods 1962-1990 and 1991-2016 and its comparison with the average temperature of the series and 1962 - 2016 for the city of Recife - PE. Source: INMET (1962-2016).

The Figure 5 shows the maximum temperature anomalies for the periods 1962-1990; 1991-2016 for the municipality of Recife - PE.

The maximum temperature anomalies for the period from 1962 to 1990 were mostly with negative anomalies ranging from -0.1 to $-1.4^{\circ} \mathrm{C}$ for the years 1962 to 1986 except for the years $1973,1983,1984$,
1985, 1987, 1988, 1989 and 1990 which had a positive anomaly and fluctuations of 0.1 to $0.4^{\circ} \mathrm{C}$. During this period, maximum temperatures prevailed within the normal range.

In the period of 1991-2016, a positive anomaly predominates in almost every year with oscillations of 0.1 to $1.1^{\circ} \mathrm{C}$. In the 2000 s there were 
the largest fluctuations in the anomaly. It should be noted that in the years 1991, 1992, 2000 and 2003 negative anomalies were registered with oscillations between 0.1 and $0.5^{\circ} \mathrm{C}$.

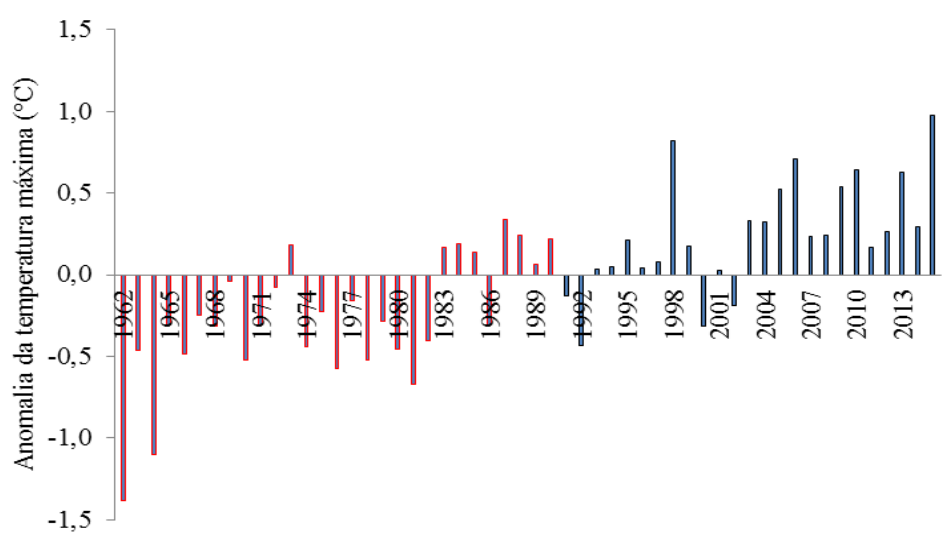

Figure 5 - Monthly average air humidity for the periods 1962-1990 and 1991-2016 and its comparison with the average temperature of the series from 1962 to 2016 for the municipality of Recife - PE.

The variability between the periods shows that the relative humidity of the average air (URM) of the period 1991-2016 during all months was below normality in relation to the two study periods, highlights the months of June, July and August where the URM almost balanced with the others. The URM of the period 1962-2016 was below the series 19621990 and above the average values of the 1991-2016 series. These fluctuations are correlated with temperature variability, cloud cover, radiation intensity and wind (Figure 6).

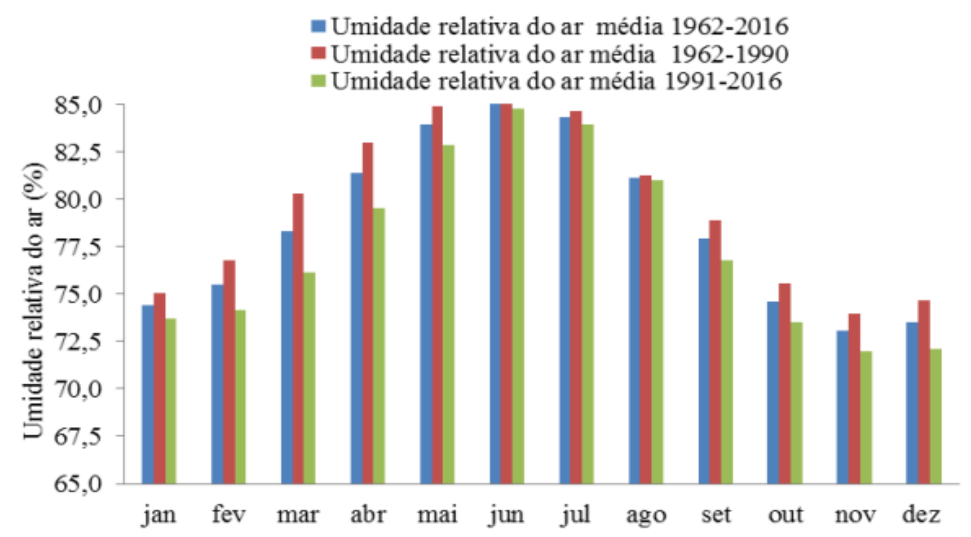

Figure 6 - Relative humidity of the monthly average air for the periods 1962-1990 and 1991-2016 and its comparison with the average temperature of the series and 1962-2016 for the municipality of Recife, PE. Source: INMET (1962-2016).

The Figure 7 shows the variability of the air relative humidity anomalies for the periods 19621990; 1991-2016 for the municipality of Recife - PE.

Comparing the two periods of URM anomalies, we highlight that the period 1962-1990 the
URM remained with positive anomalies with higher elevations than the period 1991-2016 except the years of 1967 and 1981. In the period of 1991- 2016 the predominance of URM was negative with oscillations between -0.1 to $-4 \%$. 


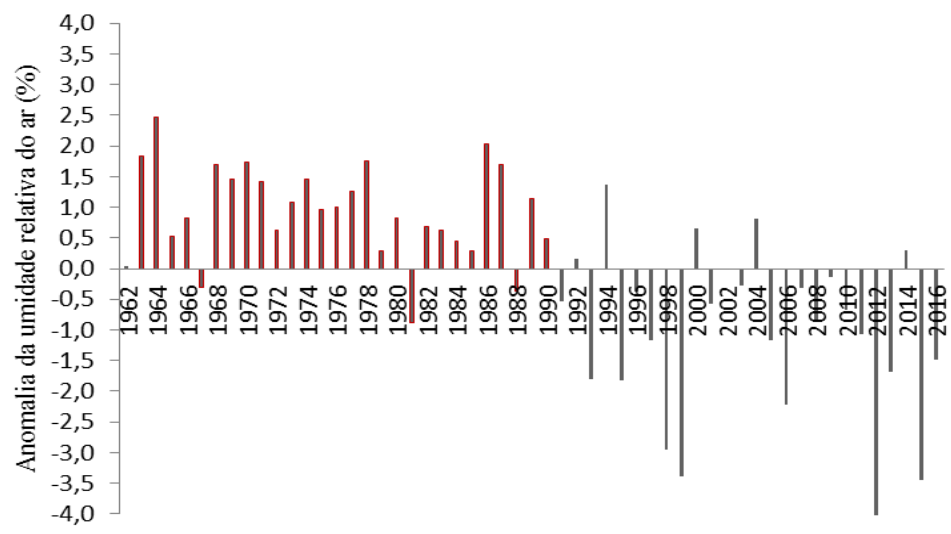

Figure 7 - Air relative humidity anomalies, for the periods 1962-1990; 1991-2016 for the municipality of Recife PE. Source: INMET (1962-2016).

\section{Conclusion}

The occurrence of a trend in urbanization and growth without planning causes variations in the urban microclimate, causing thermal discomfort and reducing the quality of life of its inhabitants. It is suggested an increase in the interbairros green areas from the afforestation that has been shown as an alternative to improve the quality of life in urban spaces.

In the last decades, a growing housing investment is highlighted either by government programs or private companies that have not contributed to the planting of new trees in these groups, for which it is important to increase the estimate of the minimum temperature by around $5^{\circ} \mathrm{C}$ while the temperature Maximum was recorded more evenly.

There is intense flow of automotive vehicles and people throughout the day due to activities related to work, commerce and services, as well as the concentration of various buildings, waterproofed areas as well as buildings, making the local air circulation difficult.

\section{References}

Arya, S.P., 2001. Introduction to Micrometerology. International Geophysics Series, 79. Academic Press, London.

Berlato, M.A., Althaus, D., 2010. Observed trend of the minimum temperature and the number of frost days in the State of Rio Grande do Sul. Agronomy Research Gaúcha 16, 7-16.

Chen, X.L., Zhao, H.M., li, P.X., Yin, Z.Y., 2006. Remote sensing image-based analysis of the relationship between urban heat island and land use / cover changes. Remote Sensing of Environment 104, 133-146.

Freitas, E.D., Dias, P.L.S., 2005. Some effects of urban areas on the generation of an island of heat.
Brazilian Journal of Meteorology 20, 355-366.

Hung, T., Uchihama, D., OCHI, S.; Yasuoka, Y., 2006. Assessment with satellite data of the urban heat island effects in Asian mega cities. International Journal of Applied Earth Observation and Geoinformation 8, 34-48,

INMET. Instituto Nacional de Meteorologia, 1992. Padrões climatológicos (1961 - 1990). Brasília.

IPCC. Intergovernmental Panel on Climate Change, 2007. Climate Change 2007: impacts, adaptation and vulnerability. Contribution of working group II to the fourth assessment report of the Intergovernmental Panel on Climate Change.

Kalnay, E., Cai, M., 2003. Impact of urbanization and land-use change on climate. Nature. 423, 528-531.

Parker, D., 2010. Urban Heat Island Effects on Estimates of Observed Climate Change. Interdisciplinary Review 1, 123-133.

Pereira, A.R., Angeloccil, L.R., Sentelhas, P.C., 2001. Agrometeorologia: fundamentos e aplicações práticas. Agropecuária, Guaíba.

Pereira, A.R., Angelocci, L.R., Sentelhas, P.C., 2002. Agrometeorologia: fundamentos e aplicações práticas. Agropecuária, Guaíba.

Rocha, L.M.V., Souza, L.C.L., Castilho, F.J.V., 2011. Ocupação de terra e ilha de calor noturno em avenidas marginais a um córrego urbano. Ambiente Construído 11, 161-175.

Sousa, W.S., Assis, J.M.O., Silva, R.F., Correia, A.M., 2013. Análise do comportamento das chuvas nos últimos 50 anos (1961 - 2011), na cidade de Recife/PE. Revista Pernambucana de Tecnologia 1, 6-14.

Thornthwaite, C.W., Mather, J.R., 1955. The Water Balance. Publications in Climatology. Drexel Institute of Technology, New Jersey.

Vincent, L.A., Peterson, T.C., Barros, V.R., 2005. Observed trends in indices of daily temperature extremes in South America 1960-2000. Journal of Climate 18, 5011-5023. 